\begin{tabular}{ccc}
\hline & International Journal of Engineering \& Technology, 7 (2.6) (2018) 71-76 \\
SPC & Website: www.sciencepubco.com/index.php/IJET \\
Review Paper & Technology \\
\hline
\end{tabular}

\title{
Applications of neural network based methods on stock market prediction: survey
}

\author{
Avilasa Mohapatra ${ }^{1}$, Smruti Rekha Das ${ }^{1}$, Kaberi Das ${ }^{1}$, Debahuti Mishra ${ }^{1}$ \\ ${ }^{I}$ Department of Computer Science and Engineering, Siksha 'O' Anusandhan Deemed to be University, Bhubaneswar, Odisha, INDIA \\ *Corresponding author E-mail: avilasa29@gmail.com
}

\begin{abstract}
Financial forecasting is one of the domineering fields of research, where investor's money is at stake due to the rise or fall of the stock prices which unpredictable and fluctuating. Basically as the demand for stock markets has been rising at an unprecedented rate so its prediction becomes all the more exciting and challenging. Prediction of the forthcoming stock prices mostly Artificial Neural Network (ANN) based models are taken into account. The other models such as Bio-inspired Computing, Fuzzy network model etc., considering statistical measures, technical indicators and fundamental indicators are also explored by the researchers in the field of financial application. Ann's development has led the investors for hoping the best prediction because networks included great capability of machine learning such as classification and prediction. Most optimization techniques are being used for training the weights of prediction models. Currently, various models of ANN-based stock price prediction have been presented and successfully being carried to many fields of Financial Engineering. This survey aims to study the mostly used ANN and related representations on Stock Market Prediction and make a proportional analysis between them.
\end{abstract}

Keywords: ANN; Financial Forecasting; Stock Market Prediction.

\section{Introduction}

Stock market involves a zone of open interest where shares are bought and sold by investors and company respectively. Here the investors include the public for the purpose of rising of the capital and a bond of security is involved in between the two. The importance of stock market can be analyzed from the fact that it provides a ground for raising money with the help of stock shares and commercial bonds. With the help of this, even the investors are benefited as they are given the shares of company's profit. As a financial barometer, stock market has influenced every strata of society, from the average family to the wealthiest. Stock market prediction involves the pre forecasting of the probable share prices based on past share prices analysis. Some of the factors which tends to affect the stock market prices are the internal developments within the company, world events (such as world war, natural disaster, and terrorism), inflation and interest rate, exchange rates with foreign currencies, and the last one is advertisement or hype of new event or product which results in promotional event.

Stock market analysis is gaining grounds of popularity may be due to its volatility, fluctuating and inconsistent nature, for which it becomes difficult for investors to preplan their strategy of investment in share market. Due to which it becomes one of the important reasons for prediction of future possible values of stock prices. The volatile nature of stock market here refers to the instabilities of the market value for returns of the shares held by the investors. Being volatile in nature it becomes difficult for accuracy and better guidance of investors. Due to its volatility, the result predicted are not $100 \%$ accurate but it helps investors to anticipate the future. Stock prediction should be as accurate as possible, so that it can be helpful, due to which technical analysis is performed prior to prediction. Analysis of previous historical data helps in getting an overview of changes in day to day basis and creating a statistical graph. Another reason for increase in the demand of stock market prediction is its challenge of being dynamic and possesses many hypothetical and experimental limitations. Any predictive model can be broadly categorized into following categories: non-parametric, parametric and semi-parametric model, where semi-parametric model includes features of both parametric and non-parametric model. Predictive modeling is a statistical based concept. The model may use a complex neural network or maybe a simple statistical formula. Some of the mostly used prediction tools in previous works are ANN (Artificial Neural Network), FLANN (Functional Link Artificial Neural Network), BPNN (Back Propagation Neural Network) and some others are RBFNN (Radial Basis Function Neural Network), ELM (Extreme Learning Machine), etc. Here, the above techniques' application in stock market prediction is analyzed. All the above techniques have their own pros and cons. The practical applications of some of the techniques on stock market analysis are proposed. Here are overviews to some of the above methods with a brief description. ANN is an interconnected group of nodes, which functions similarly to that of a human brain and is very much preferred due to its superiority and variations [1]. ANN contains several other models, for example, MLP (Multi-Layer Perceptron Network), Autoencoder etc. Hadavandi et al. [2] anticipated a ANN model based on genetic fuzzy system for predicting the next day's stock prices as well as overcoming the shortcomings of ANN model alone, as every Artificial Intelligence (AI) model has its own pros and cons. BPNN is one of the techniques which are most often used for stock market prediction due to its complexity and amalgamated multilayered neural network [3] and here the author proposes a modified BPNN technique overcoming some of its previous drawbacks. Zhang et al. [4] proposed a hybridized model based on EMDBPNN, where EMD (Empirical Mode Decomposition) is used to 
break down the time series dataset to IMF (Intrinsic Mode Function) at several levels and then BPNN is used for training. There are a lot of complexities and differences between multi-layer neural network and single layer neural network. Due to which FLANN was developed to minimize such complexities and the shortcomings [5]. Bebarta et al. compared all the types of FLANN models and proved its efficiency and simplicity compared to other multi-layer ANN models [6]. RBFNN were at first used for solving the interpolation problems (fitting a curve exactly among a set of pints) [7] Similar to FLANN, RBFNN is also used for minimizing limitations of ANN model in stock prediction [8]. ELM are feed-forward neural networks which is being used for the process of classification, clustering, feature selection, regression sparse approximation, and compression in single or multi-layer hidden nodes in which the parameters need not be adjusted. Wang et al. [9] proposed a multikernel learning based ELM model which not only enhances the performance but also is a fast learning model. The model includes MKL-ELM, K-ELM, SVM which is developed by using HKEx 2001 stock market datasets and proves to be better in comparison to B-ELM and BPNN and MKL-ELM proved to better amongst all RBFNN is a feed-forward neural network which is double layered. It was first presented as a solution in the real multivariate interpolation problem. Rakhi Mahanta et al. proposed an optimized RBF network model and compared it with MLP for proving its authenticity in the field of prediction. Here Nifty data set is used for experiment purpose [10].

The following contents of the paper consists of the following: section 2 focuses on the methods of application of different techniques and their hybrid use in stock market prediction and a comparative study along with other optimized recently developed models. This is followed by a summarization of ANN models as the conclusion in the last section.

\section{Literature survey}

\subsection{ANN}

The future of an investor in a stock market highly depends on the future of the Sensex which is highly unpredictable; Even a small investor can gain a lot. Due to which a lot of interest are paid by the researchers to propose an algorithm which fulfills all requirements and gives a nearly accurate model. Due to the complex, volatile and fluctuating features of the stock market's everyday prices, it is highly difficult to predict an accurate model for such dynamic characteristics. For this reason, several distinct models have been tried in all the fields of financial market, which still contain their own merits and demerits. The prediction approaches fall generally into three categories. First is fundamental analysis, where the company's past performance is evaluated along with trustworthiness of its accounts. Here the company's historical as well as present state is taken into account. Second is, technical analysis, seek to foresee the future prices based on the trends of the past price. Most common factors are the company's economic conditions and its working circumstances. Lastly the technological analysis, which involves the use of data mining models such as ANN, SVM (Support Vector Machine), GA (Genetic Algorithm) Fuzzy Logic, evolutionary computation, etc. The model which is a lot preferred for stock market analysis in ANN is feed-forward neural network.

ANN has been originating to deliver very promising results in case of stock prediction. A several dynamic and hybrid models have been proposed which gives promising results in this regard. Kara et al. presented a comparative analysis between ANN and SVM model by attempting to predict the course of movement of stock prices using the Istanbul stock exchange. It was figured that both the process can be equally emphasized and taken into account in stock prediction. But ANN performed in an average a slight better in performance as compared to SVM [11]. Laboissiere et al. proposed a model based [12] on ANN with an objective to solve the difficulty of calculation of maximum and minimum day stock prices using
NASDAQ stock exchange indices for Brazilian Distribution Company was found to be effective. The prediction's performance was measured by involving Mean Absolute Error (MAE), Root Mean Square Error (RMSE) and Mean Absolute Percentage Error (MAPE) calculations. Moghaddam et al. in the paper tries to perform the [13] functioning mechanism and the effect of ANN on the daily NASDAQ stock exchange prediction. The above model uses the values of NASDAQ exchange rate of last four and nine working days along with week's day as the input parameters and it was proved that there is no difference between the performance of the two, may it be last four or nine working days. Both showed nearly the same value. Guresan et al. compares different types of ANN model, which are dynamic in nature, to prove the accuracy of each model for stock market [14] prediction and to provide an accurate model to reduce the shortcomings of using ANN model here. The model used here are MLP, DAN2 (Dynamic ANN), the hybridized ANN which uses GARCH (Generalized Autoregressive Conditional Heteroscedasticity) for the extraction of innovative input variables. Gocken et al. uses hybrid ANN for capturing the connection between the stock market and the technical indicators for the duration undertaken, which [15] consists of exploiting proficiencies of GA and Harmony Search (HS), indicating the use of selection of the most appropriate technical indicator. Here both HS-ANN and GA-ANN were highly efficient for stock analysis but both had some shortcomings which could be avoided with the help of selection, cross-over and mutation operators. There is a list of other proposed model from [16-23] given in the Table 1 which clearly depicts the further use of ANN

model.

\subsection{BPNN}

Due to the noisy data of stock prices, it is quite a difficult task for the researchers to make a tool with accurate prediction. So Wang et al. proposed a BPNN based [24] approach called as Wavelet Denoising-based Back Propagation (WDBP) neural network. Here Shanghai Composite Index time period of January 1993 to December 2009 is taken into account for proving WDBP's efficiency in stock prediction. The projected technique is compared with simple BPNN network. Here the dataset is divided into layers, as each level contains a low and a high occurrence. Then BPNN is set up on lowfrequency single for prediction of future value. Here the Wavelet transform is a very efficient preprocessing tool. Hsieh proposed an integrated design of [25] experiment (DOE) and BPNN for the construction of a robust platform to improve the estimation accuracy under the influence of robust DOE-based predictor. The Taiwan Stock Exchange (TWSE) and Hang Seng Index (HSI) are taken as dataset for the implementation of the above model. The proposed model can very efficiently increase the rate of prediction of stock's discrepancy. Yizhen et al. projected a hybrid model involving [26] BPNN and genetic algorithm (GA) on the Shanghai stock index. The model proposed is an intricate nonlinear stochastic system which has high application value. Here BPNN is used in forecasting the trend and GA is used in optimization of to optimize the parameter, such as weight and structure. Khao et al. proposed a BPNN model trained by [27] time and profit factor along with simple recurrent neural network on S\&P 500 of U.S. stock exchange. It was proposed for the use of GA as the future work to be implemented as this model worked perfectly with the stock prices. Table 2 portrays some other enhanced models of BPNN from [28 - 30].

\subsection{FLANN}

A FLANN model can also be of different types like Power FLANN (PFLANN), Legendre FLANN (LeFLANN), Laguerre FLANN (LFLANN) and Chebyshev FLANN (CFLANN). Each of the above models can be used for time series data prediction. Das et al. gave forward a FLANN model trained by fuzzy for prediction of the closing price of Yahoo Inc, Nokia and Bank of America [31]. The result is then put in comparison to the constraints of the FLANN model trained by GA. A trigonometric FLANN model projected by Majhi 
et al. for short term and long term prediction [32] of prices of S\&P 500 and DJIA stock price. The developed model uses the LMS (least mean square) as well as the RLS (recursive least square) for the weights of the model, to be trained as per requirements. In comparison to LMS based prediction, RLS is more appropriate because of requiring significantly less test to train the model. Table 3 portrays some other enhanced techniques of FLANN from [33-36].

Table 1: The Findings of the Model Using ANN Technique

\begin{tabular}{|c|c|c|c|}
\hline Domain & Sources of Data & Proposed model & Findings \\
\hline $\begin{array}{l}\text { Stock Mar- } \\
\text { ket Predic- } \\
\text { tion }\end{array}$ & $\begin{array}{l}\text { NSE data ( } 2008 \text { to } \\
\text { 2012), New York stock } \\
\text { exchange }\end{array}$ & $\begin{array}{l}\text { ANN model (MLP) using C\# pro- } \\
\text { gramming language }\end{array}$ & $\begin{array}{l}\text { Stock market prediction requires large amount of data for the tools } \\
\text { to be trained. }\end{array}$ \\
\hline $\begin{array}{l}\text { Stock Mar- } \\
\text { ket Predic- } \\
\text { tion }\end{array}$ & $\begin{array}{l}\text { Hana, Synex, LPN stock } \\
\text { prices of Thailand }\end{array}$ & $\begin{array}{l}\text { Simple static cascade-forward } \\
\text { back-propagation } \\
\text { ANN }\end{array}$ & $\begin{array}{l}\text { Ann is used for calculating the effects of stock repurchase and it is } \\
\text { fruitful after several times the dataset is trained. }\end{array}$ \\
\hline $\begin{array}{l}\text { Stock Mar- } \\
\text { ket Predic- } \\
\text { tion }\end{array}$ & $\begin{array}{l}\text { OTC Exchange of Tai- } \\
\text { wan }\end{array}$ & $\begin{array}{l}\text { ANN and DT (C\&RT) (Decision } \\
\text { tree) as well as a hybrid model } \\
\text { (both ANN and DT) }\end{array}$ & $\begin{array}{l}\text { ANN model is far more efficient than the C\&RT model or hybrid } \\
\text { model. The proposed hybrid model needs development. }\end{array}$ \\
\hline $\begin{array}{l}\text { Stock Mar- } \\
\text { ket Predic- } \\
\text { tion }\end{array}$ & $\begin{array}{l}\text { Shanghai stock ex- } \\
\text { change }\end{array}$ & sset pricing model & $\begin{array}{l}\text { CAPM outperform Fama and French's ( } 3 \text {-factor) model in stock } \\
\text { market prediction. }\end{array}$ \\
\hline $\begin{array}{l}\text { Stock Mar- } \\
\text { ket Predic- } \\
\text { tion }\end{array}$ & Petrobras' PETR4 stock & $\begin{array}{l}\text { ANN with different analysis tech- } \\
\text { nique }\end{array}$ & $\begin{array}{l}\text { ANN was very fruitful for prediction as well as enhancement of the } \\
\text { directional prediction index. }\end{array}$ \\
\hline $\begin{array}{l}\text { Stock Mar- } \\
\text { ket Predic- } \\
\text { tion }\end{array}$ & Tehran Stock Exchange & $\begin{array}{l}\text { MLP along with Principal Compo- } \\
\text { nent Analysis(PCA) }\end{array}$ & $\begin{array}{l}\text { ANN model has proven its superiority compared to others. Other } \\
\text { models like genetic algorithm models, Fraktal models and non-lin- } \\
\text { ear regression models can also be applied here. }\end{array}$ \\
\hline $\begin{array}{l}\text { Stock Mar- } \\
\text { ket Predic- } \\
\text { tion }\end{array}$ & $\begin{array}{l}\text { Microsoft Corp., Gold- } \\
\text { man Sachs } \\
\text { Group Inc. stock }\end{array}$ & $\begin{array}{l}\text { Bayesian regularized artificial neu- } \\
\text { ral network }\end{array}$ & $\begin{array}{l}\text { The projected model performed as good as other progressive mod- } \\
\text { els without preprocessing the need of data. }\end{array}$ \\
\hline $\begin{array}{l}\text { Stock Mar- } \\
\text { ket Predic- } \\
\text { tion }\end{array}$ & $\begin{array}{l}\text { Tehran Stock Market } \\
(2007-2012)\end{array}$ & $\begin{array}{l}\text { integration fuzzy C-means (FCM), } \\
\text { ANN and data envelopment analy- } \\
\text { sis (DEA) }\end{array}$ & $\begin{array}{l}\text { It is fruitful for companies where data is available in partial form } \\
\text { and not in total, as it forms clusters. }\end{array}$ \\
\hline
\end{tabular}

Table 2: The Findings of the Model Using BPNN Technique

\begin{tabular}{|c|c|c|c|}
\hline Domain & Sources of Data & Proposed model & Findings \\
\hline Stock Market Prediction & $\begin{array}{l}\text { Taiwan Top } 50 \text { Exchange Traded } \\
\text { Fund (ETF), Shenzhen Compo- } \\
\text { site, and S\&P } 500\end{array}$ & $\begin{array}{l}\text { Dynamic normalized BPNN } \\
\text { (BPNN with novel normalized } \\
\text { function) }\end{array}$ & $\begin{array}{l}\text { This model provides a methodology of de- } \\
\text { signing parameters for better performance, } \\
\text { thus giving a comparatively a good result. }\end{array}$ \\
\hline Stock Market Prediction & $\begin{array}{l}\text { L\&T stock market data, Air } \\
\text { Quality data, Surface roughness, } \\
\text { Concrete Strength data }\end{array}$ & $\begin{array}{l}\text { GA and BPNN based Hybrid } \\
\text { model }\end{array}$ & $\begin{array}{l}\text { The proposed model proves to be in better } \\
\text { standards compared to BPNN model in both } \\
\text { multivariate and univariate data sets. }\end{array}$ \\
\hline Stock Market Prediction & S\&P 500 & $\begin{array}{l}\text { Hybrid model of improved bacte- } \\
\text { rial chemotaxis optimization } \\
(\mathrm{BCO}) \text { and BPNN }\end{array}$ & $\begin{array}{l}\text { The proposed model is better in performance } \\
\text { in learning capacity and generalization. }\end{array}$ \\
\hline
\end{tabular}

Table 3: The Findings of the Model Using FLANN Technique

\begin{tabular}{|c|c|c|c|}
\hline Domain & Sources of Data & Proposed model & Findings \\
\hline $\begin{array}{l}\text { Stock Market Predic- } \\
\text { tion }\end{array}$ & $\begin{array}{l}\text { DJIA } \\
\text { S\&P500 stock indices }\end{array}$ & $\begin{array}{l}\text { Hybrid FFLANN (Feedback FLANN) } \\
\text { with RLS }\end{array}$ & $\begin{array}{l}\text { The model projected is superior in } \\
\text { comparison to MLANN, RBFNN, } \\
\text { and SVM under similar conditions. }\end{array}$ \\
\hline $\begin{array}{l}\text { Stock Market Predic- } \\
\text { tion }\end{array}$ & S\&P500and NIKKEI 225 data sets & $\begin{array}{l}\text { recurrent computationally efficient } \\
\text { FLANN (RCEFLANN) along with adap- } \\
\text { tive bio-inspired Firefly algorithm along } \\
\text { with New Jersey- } \\
\text { Maryland (PJM) energy market }\end{array}$ & $\begin{array}{l}\text { It takes less computational overhead } \\
\text { to predict acceptable consequences. } \\
\text { And is even good at predicting elec- } \\
\text { tricity price prediction as the data set } \\
\text { is taken for surety of result. }\end{array}$ \\
\hline $\begin{array}{l}\text { Mutual Fund Predic- } \\
\text { tion }\end{array}$ & $\begin{array}{l}\text { Birla Sun Life Equity Fund Growth, } \\
\text { Franklin India Bluechip Fund - } \\
\text { Growth, HDFC Top200- Growth, } \\
\text { ICICI pro. Top100-Growth, } \\
\text { UTI Equity Fund-Growth }\end{array}$ & $\begin{array}{l}\text { Non-Linear improvised FLANN based } \\
\text { prediction model }\end{array}$ & $\begin{array}{l}\text { This model is used to calculate net } \\
\text { asset value (NAV) of Indian stock } \\
\text { exchanges which includes fewer } \\
\text { computational weight and fast pre- } \\
\text { diction capacity. }\end{array}$ \\
\hline $\begin{array}{l}\text { Stock Market Predic- } \\
\text { tion }\end{array}$ & $\begin{array}{l}\text { BSE (Bombay Stock Exchange), } \\
\text { NSE, INFY }\end{array}$ & $\begin{array}{l}\text { Differential } \\
\text { Evolution based FLANN }\end{array}$ & $\begin{array}{l}\text { The DE improved FLANN affords } \\
\text { enhance performance as compared } \\
\text { to RMSE and MAPE. }\end{array}$ \\
\hline
\end{tabular}

\subsection{ELM}

ELM can be implemented in different methods like classification, compression and spare coding in different methods, due to which multi-ELMs are used for the formation of multi-hidden layer network, deep learning, or hierarchical networks [37-39]. Gocken et al. developed an improved ELM model [40] consisting of an integration of GA, DE, PSO and weighted superposition attraction (WSA). The model was carried on the stock exchange of turkey. It was concluded that even after the presence of highly fluctuating data of stock prices the model was a great success in forecasting technique. They also suggested that the model could be tried on other stocks and instead of technical indicators; fundamental indicators could also be used. Ravi et al. develops a model on the oil and gas indices of Bombay stock exchange (BSE), as the sequential 
alternatives of ELM, which is compared to BPNN with single hidden layer. The model is not in prerequisite of computation of the inverse of any matrix and has simple initialization [41]. Cavalcante et al. proposed a trader agent [42] which can not only compute technical indicators by itself but also take self-decisions on buying and selling of stocks for benefit. The involved mediator is built on a Single-hidden Layer Feedforward Neural Network (SLFN) jointly trained with OS-ELM (online sequential ELM), an alternative of ELM that can obtain data one-by-one and dynamically provide accommodated modifications in the market. The model is constructed on Brazilian stock exchange with increased amount of financial gain. Again the same author proposed another hybrid model of OSELM which [43] consists of explicit drift detection. Here the decision model gets updated in the presence of perceived drift in data and speeding up the forecast time by preserving equivalent precision. The data sets being used for estimating the accuracy of the proposed model are S\&P 500 Index, Shanghai SSE Composite Index, and Apple Inc. stock prices.

$\mathrm{X}$. Wang et al. proposed an OS-ELM with kernel-based model (OSELMK) after nonstationary stock price prediction, which was applied [44] to (Dow Jones Industrial Average) DJIA stock exchange. The above model can easily adapt to tune when new samples are added or removed. The speed of prediction is much faster as compared to online support vector regression (OLSVR) and ELMK. Table 4 portrays some other enhanced techniques of ELM from [4550].

Table 4: The Findings of the Model Using ELM Technique

\begin{tabular}{|c|c|c|c|}
\hline Domain & Sources of Data & \multirow{2}{*}{$\begin{array}{l}\text { Proposed model } \\
\text { Hybridized ELM model i.e. an ELM } \\
\text { model consisting of Jaya optimization } \\
\text { technique }\end{array}$} & Findings \\
\hline $\begin{array}{l}\text { Forex Market Predic- } \\
\text { tion }\end{array}$ & $\begin{array}{l}\text { USD to INR exchange rate } \\
\text { and USD to EURO exchange } \\
\text { rate }\end{array}$ & & $\begin{array}{l}\text { The model performs better than any other } \\
\text { model if same condition is applied to } \\
\text { FLANN and NN. }\end{array}$ \\
\hline $\begin{array}{l}\text { Stock Market Predic- } \\
\text { tion }\end{array}$ & $\begin{array}{l}\text { TianChi and BCS Stock Ex- } \\
\text { change }\end{array}$ & $\begin{array}{l}\ell_{2,1} \text {-norm and Random Fourier Mapping } \\
\text { based Extreme Learning } \operatorname{Machine}\left(\ell_{2,1}\right. \\
\text { RF-ELM })\end{array}$ & $\begin{array}{l}\text { Due to the presence of } 12,1 \text { RF-ELM, the in- } \\
\text { appropriate and terminated hidden neurons } \\
\text { are eliminated to form a more discriminative } \\
\text { and compressed hidden layer }\end{array}$ \\
\hline $\begin{array}{l}\text { Stock Market Predic- } \\
\text { tion }\end{array}$ & $\begin{array}{l}\text { Chinese segmentation soft- } \\
\text { ware ICTCLAS for segment- } \\
\text { ing the sentences of market } \\
\text { news and stock prices }\end{array}$ & $\begin{array}{l}\text { A feature selection algorithm normalized } \\
\text { relative discriminant Criterion (NRDC), } \\
\text { as well as a new feature weighting algo- } \\
\text { rithm (N-TF-IDF) }\end{array}$ & $\begin{array}{l}\text { The proposed achieve better speed and accu- } \\
\text { racy in case of prediction in most cases. As } \\
\text { it is a kernel-based learning model it can be } \\
\text { extended to multi kernel-based learning } \\
\text { model. }\end{array}$ \\
\hline $\begin{array}{l}\text { Stock Market Predic- } \\
\text { tion }\end{array}$ & $\begin{array}{l}\text { daily value of Petroleum sec- } \\
\text { tor Index }\end{array}$ & $\begin{array}{l}\text { adaptive ensemble models of ELMs (AD- } \\
\text { ELM) }\end{array}$ & $\begin{array}{l}\text { The model here is used for outlier forecast- } \\
\text { ing and outperforms the methods based on } \\
\text { autoregression and ELM models. }\end{array}$ \\
\hline $\begin{array}{l}\text { Stock Market Predic- } \\
\text { tion }\end{array}$ & $\begin{array}{l}\text { Sea-water } \\
\text { temperature, Sunspots and } \\
\text { Santa Fe A }\end{array}$ & $\begin{array}{l}\text { Optimally Pruned Extreme Learning Ma- } \\
\text { chine (OP-ELM) }\end{array}$ & $\begin{array}{l}\text { OP-ELM is robust against peripheral or in- } \\
\text { terrelated variable. The model can be used } \\
\text { without computationally substantial variable } \\
\text { selection techniques. }\end{array}$ \\
\hline $\begin{array}{l}\text { Stock Market Predic- } \\
\text { tion }\end{array}$ & \multicolumn{2}{|l|}{$\begin{array}{l}\text { Shanghai stock index, } \\
\text { Shenzhenv component, } \\
\text { Vanke, Yunnan baiyao, China Petro } \\
\text { Chemical, Baotou Rare Earth, He- } \\
\text { fei, Fengle Seed, China Satellite }\end{array}$} & $\begin{array}{l}\text { omparison to single feature wavelet tech- } \\
\text { de, the recognized results were found to } \\
\text { nore reliable, as it handles more infor- } \\
\text { ion from the Sensex and prevents "mask- } \\
\text { effect". }\end{array}$ \\
\hline
\end{tabular}

\subsection{RBFNN}

RBFNN is a two-layer feed-forward neural network. It was first presented as a solution in the real multivariate interpolation problem [51]. Sun et al. the method collectives the optimal [52] partition algorithm (OPA) with the RBFNN. The proposed model is compared with the HCM (hard c-means) algorithm shows that the suggested OPA method recollects obvious benefits in the precision of forecasting, simplification, and predicting trends. C. Quek et al. evaluated the effectiveness of 4 models of [53] neural network such as Feed Forward Neural Network, RBFNN, ANFIS (Adaptive Neuro-Fuzzy Inference System) and RSPOP (Rough Set based Pseudo Outer Product Rule) in predicting the impact of news on stock market prediction. Here RBFNN has considerably better values than FFNN but the best values are RSPOP with marginal error values. Feng et al. proposed an evolutional RBFNN on Taiwan stock index (TAIEX) including [54] a step-wise regression analysis (SRA). Computational models TAIEX are compared with other learning methodologies, which illustrates better presentation, not only increases the exactness of the stock price prediction but also enhances the win rate in the TAIEX trends. Minakshi Rout et al. worked on the optimization [55] of RBFNN. Accordingly, the RBFNN is considered as the best analyst. Wei Shen et al. Wu developed a model using RBFNN improved by artificial fish swarm (AFS) algorithm. AFS is used for optimizing [56] the k-means algorithm which leads to a better precision.

\section{Conclusion}

This paper demonstrated the different NNs model currently in use for predicting financial time series' accuracy, speed and its parameters optimization. It gave emphasize basically on ANN, BPNN, RBFN, FLANN, ELM. Each and every model has their own merits and demerits and their superiority on other model. Amongst all ELM is the latest model used and gets easily hybridized with other explicit models. From here, it can be drawn that, ANN has the aptitude of generalizing and correctly inferring parts of the sample data set even if the sample contains unwanted information. Neural Network captures understated functional relationships even if it is hard to describe. Neural network model is accomplished in such a way that it learns from experience and provides a practically feasible way to solve real-world problems.

\section{References}

[1] Wanjawa, Barack Wamkaya, and Lawrence Muchemi. "ANN Model to Predict Stock Prices at Stock Exchange Markets." arXiv preprint arXiv:1502.06434 (2014).

[2] Esmaeil Hadavandi, Hassan Shavandi, Arash Ghanbari, "Integration of genetic fuzzy systems and artificial neural networks for stock price forecasting", In Knowledge-Based Systems, Volume 23, Issue 8 , 2010, Pages 800-808. https://doi.org/10.1016/j.knosys.2010.05.004.

[3] F. Mithani, S. Machchhar and F. Jasdanwala, "A modified BPN approach for stock market prediction," 2016 IEEE International Conference on Computational Intelligence and Computing Research (ICCIC), Chennai, 2016, pp. 1-4. https://doi.org/10.1109/ICCIC.2016.7919718. 
[4] Zhang, Chengzhao, and Heping Pan. "A novel hybrid model based on EMD-BPNN for forecasting US and UK stock indices." In Progress in Informatics and Computing (PIC), 2015 IEEE International Conference on, pp. 113-117. IEEE, 2015.

[5] Patra, Jagdish C., Nguyen C. Thanh, and Pramod K. Meher. "Computationally efficient FLANN-based intelligent stock price prediction system." In Neural Networks, 2009. IJCNN 2009. International Joint Conference on, pp. 2431-2438. IEEE, 2009. https://doi.org/10.1109/IJCNN.2009.5178594.

[6] Dwiti Krishna Bebarta, Birendra Biswal, Ajit Kumar Rout, P. K Dash, "Forecasting and Classification of Indian Stocks Using Different Polynomial Functional Link Artificial Neural Networks", In India Conference (INDICON), 2012 Annual IEEE, pp. 178-182, IEEE, 2012.

[7] C. Quek, P. Cheng and A. Jain, "Predicting impact of news on stock price: An evaluation of neuro fuzzy systems," 2007 IEEE Congress on Evolutionary Computation, Singapore, 2007, pp. 1226-1233. https://doi.org/10.1109/CEC.2007.4424610.

[8] Hsuan-Ming Feng, Hsiang-Chai Chou, Evolutional RBFNs prediction systems generation in the applications of financial time series data, In Expert Systems with Applications, Volume 38, Issue 7, 2011, Pages 8285-8292, ISSN 0957-4174.

[9] F.Wang, Z. Zhao, X. Li, F. Yu and H. Zhang, "Stock volatility prediction using multi-kernel learning based extreme learning machine," 2014 International Joint Conference on Neural Networks (IJCNN), Beijing, 2014, pp. 3078-3085. https://doi.org/10.1109/IJCNN.2014.6889651.

[10] Rakhi Mahanta, Trilok Nath Pandey, Alok Kumar Jagadev, Satchidananda Dehuri, "Optimized Radial Basis Functional Neural Networkfor Stock Index Prediction", International Conference on Electrical, Electronics, and Optimization Techniques (ICEEOT) 2016, pp. 1252-1257. IEEE, 2016. https://doi.org/10.1109/ICEEOT.2016.7754884.

[11] Kara, Yakup, Melek Acar Boyacioglu and Omer Kaan Baykan, "Predicting direction of stock price index movement using artificial neural networks and support vector machines: The sample of the Istanbul Stock Exchange." Expert systems with Applications 38, no. 5(2011):5311-5319. https://doi.org/10.1016/j.eswa.2010.10.027.

[12] Laboissiere, Ricardo A.S. Fernandes, Guilherme G. Lage, "Maximum and minimum stock price forecasting of Brazilian power distribution companies based on artificial neural networks." Applied Soft Computing https://doi.org/10.1016/j.asoc.2015.06.005.

[13] Amin Hedayati Moghaddam, Moein Hedayati Moghaddam, Morteza Esfandyari, "Stock market index prediction using artificial neural network." Journal of Economics, Finance and Administrative Science 21, no. 41(2016): https://doi.org/10.1016/j.jefas.2016.07.002

[14] Erkam Guresen, Gulgun Kayakutlu, Tugrul U. Daim, "Using artificial neural network models in stock market index prediction." Expert Systems with Applications 38, no. 8(2011): 10389-10397 https://doi.org/10.1016/j.eswa.2011.02.068.

[15] Mustafa Gocken, Mehmet Ozcalici, Asli Boru, Ayse Tugba Dosdogruc, "Integrating metaheuristics and Artificial Neural Networks for improved stock price prediction" Expert Systems with Ap$\begin{array}{llll}\text { plications } & 44 & \text { (2016): } & 320-331\end{array}$ https://doi.org/10.1016/j.eswa.2015.09.029.

[16] Barack Wamkaya Wanjawa, Lawrence Muchemi, "ANN Model to Predict Stock Prices at Stock Exchange Markets." arXiv preprint arXiv: 1502.06434(2014).

[17] Karn Meesomsarn, Roungsan Chaisricharoen, Boonruk Chipipop, Thongchai Yooyativong, "Forecasting the Effect of Stock Repurchase via an Artificial Neural Network." In ICCAS-SICE, 2009, pp. 2573-2578. IEEE, 2009.

[18] Tsung-Sheng Chang, "A comparative study of artificial neural networks, and decision trees for digital game content stocks price prediction." Expert Systems with Applications 38, no. 12(2011): 1484614851. https://doi.org/10.1016/j.eswa.2011.05.063.

[19] Qing Cao, Karyl B. Leggio, Marc J. Schniederjans, "A comparison between Fama and French's model and artificial neural networks in predicting the Chinese stock market." Computers \& Operations Research 32, no. 10(2005), 2499-2512. https://doi.org/10.1016/j.cor.2004.03.015.

[20] Fagner A. de Oliveira, Cristiane N. Nobre, Luis E. Zarate, "Applying Artificial Neural Networks to prediction of stock price and improvement of the directional prediction index - Case study of PETR4, Petrobras, Brazil", Expert Systems with Applications 40, no. 18(2013), 7596-7606. https://doi.org/10.1016/j.eswa.2013.06.071.

[21] Javad Zahedi, Mohammad Mahdi Rounaghi, "Application of artificial neural network models and principal component analysis method in predicting stock prices on Tehran Stock Exchange", Physica A: Statistical Mechanics and its Applications 438(2015), 178-187. https://doi.org/10.1016/j.physa.2015.06.033.

[22] Jonathan L. Ticknor, "A Bayesian regularized artificial neural network for stock market forecasting", Expert Systems with Applications 40, no. 14(2013), 5501-5506. https://doi.org/10.1016/j.eswa.2013.04.013

[23] Mustafa Jahangoshai Rezaee, Mehrdad Jozmaleki, Mahsa Valipour, "Integrating dynamic fuzzy C-means, data envelopment analysis and artificial neural network to online prediction performance of companies in stock exchange", Physica A: Statistical Mechanics and its Applications, 489 (2018), 78-93. https://doi.org/10.1016/j.physa.2017.07.017.

[24] Jian-Zhou Wang, Ju-Jie Wang, Zhe-George Zhang, Shu-Po Guo, "Forecasting stock indices with back propagation neural network.", Expert Systems with Applications, 38, no: 11(2011),14346-14355. https://doi.org/10.1016/j.eswa.2011.04.222.

[25] Ling-Feng Hsieh, Su-Chen Hsieh, Pei-Hao Tai, "Optimize stock price variation prediction via DOE and BPNN." In Supply Chain Management and Information Systems (SCMIS), 2010 8th International Conference on, pp.1-7. IEEE, 2010.

[26] LI Yizhen, Zeng Wenhua, Lin ling, Wu jun, Lu Gang, "The forecasting of Shanghai Index trend Based on Genetic Algorithm and Back Propagation Artificial Neural Network Algorithm."The 6th International Conferencein Computer Science \& Education (ICCSE), pp. 420-424, IEEE, 2011.

[27] Nguyen Lu Dang Khoa, Kazutoshi Sakakibara, Ikuko Nishikawa, "Stock Price Forecasting using Back Propagation Neural Networks with Time and Profit Based Adjusted Weight Factors", In SICEICASE, International Joint Conference, pp.5484-5488. IEEE, 2006.

[28] Chia-Chi Chen, Chun Kuo, Shu-Yu Kuo, Yao-Hsin Chou, "Dynamic normalization BPN for stock price forecasting." In Systems, Man, and Cybernetics (SMC), 2015 IEEE International Conference on, pp. 2855-2860, IEEE, 2015. https://doi.org/10.1109/SMC.2015.497.

[29] Aishwarya D C, C. Narendra Babu, "Prediction Of Time Series Data Using GA-BPNN based Hybrid ANN Model", In Advance Computing Conference (IACC), 2017 IEEE 7th International, pp. 848-853, IEEE, 2017. https://doi.org/10.1109/IACC.2017.0174.

[30] Zhang Yudong, Wu Lenan, "Stock market prediction of S\&P 500 via combination of improved BCO approach and BP neural network." Expert Systems with Applications 36, no. 5 (2009), 8849-8854. https://doi.org/10.1016/j.eswa.2008.11.028.

[31] Soumya Das, Abhimanyu Patra, Sarojananda Mishra, Manas Ranjan Senapati, "A self-adaptive fuzzy-based optimized functional link artificial neural network model for financial time series prediction", International Journal of Business Forecasting and Marketing Intelli$\begin{array}{lllll}\text { gence } 2, & \text { no. } & 1 & \text { (2015): } & 55-77 .\end{array}$ https://doi.org/10.1504/IJBFMI.2015.075358.

[32] Ritanjali Majhi, G. Panda, G. Sahoo, "Development and performance evaluation of FLANN based model for forecasting of stock markets", Expert Systems with Applications 36 (2009), 6800-6808. https://doi.org/10.1016/j.eswa.2008.08.008.

[33] C.M. Anish, Babita Majhi, "Hybrid nonlinear adaptive scheme for stock market prediction using feedback FLANN and factor analysis.", Journal of the Korean Statistical Society 45 (2016), 64-76. https://doi.org/10.1016/j.jkss.2015.07.002.

[34] C. M. Anish1, Babita Majhi, "Net Asset Value Prediction using FLANN Model.", International Journal of Science and Research (IJSR) 4, no. 2(2015): 2222-2227.

[35] Rout, Ajit Kumar, R. Bisoi, and P. K. Dash. "A low complexity evolutionary computationally efficient recurrent Functional link Neural Network for time series forecasting." In Power, Communication and Information Technology Conference (PCITC), 2015 IEEE, pp. 576582. IEEE, 2015.

[36] Puspanjali Mohapatra, Alok Raj, "Indian Stock Market Prediction Using Differential Evolutionary Neural Network Model", International Journal of Electronics Communication and Computer Technology (IJECCT), Volume 2 Issue 4 (2012).

[37] Huang, Guang-Bin, Zuo Bai, and Liyanaarachchi Lekamalage Chamara Kasun, and Chi Man V ong (2015). "Local Receptive Fields Based Extreme Learning Machine." IEEE Computational Intelligence Magazine. 10: 18-29. https://doi.org/10.1109/MCI.2015.2405316.

[38] Tang, Jiexiong, Chenwei Deng, and Guang-Bin Huang (2016)."Extreme Learning Machine for Multilayer Perceptron." IEEE Transactions on Neural Networks and Learning Systems. 27: 809-821. https://doi.org/10.1109/TNNLS.2015.2424995.

[39] Zhu, W.; Miao, J.; Qing, L.; Huang, G. B. (2015-07-01). "Hierarchical Extreme Learning Machine for unsupervised representation 
learning.” 2015 International Joint Conference on Neural Networks (IJCNN): 1-8.

[40] M. Gocken, A. Boru, A. T. Dosdogru and M. Ozcalici, "Hybridizing extreme learning machine and bio-inspired computing approaches for improved stock market forecasting," 2017 International Artificial Intelligence and Data Processing Symposium (IDAP), Malatya, 2017, pp. 1-6.

[41] A. S. Ravi, A. Sarvesh and K. George, "Sequential ELM for financial markets," 2016 Second International Conference on Cognitive Computing and Information Processing (CCIP), Mysore, 2016, pp. 1-6. https://doi.org/10.1109/IJCNN.2015.7280721.

[42] R. C. Cavalcante and A. L. I. Oliveira, "An autonomous trader agent for the stock market based on online sequential extreme learning machine ensemble," 2014 International Joint Conference on Neural Networks (IJCNN), Beijing, 2014, pp. 1424-1431.

[43] R. C. Cavalcante and A. L. I. Oliveira, "An approach to handle concept drift in financial time series based on Extreme Learning Machines and explicit Drift Detection," 2015 International Joint Conference on Neural Networks (IJCNN), Killarney, 2015, pp. 1-8.

[44] Xinying Wang, Min Han, Online sequential extreme learning machine with kernels for nonstationary time series prediction, In Neurocomputing, Volume 145, 2014, Pages 90-97. https://doi.org/10.1016/j.neucom.2014.05.068.

[45] Smruti Rekha Das, Debahuti Mishra, Minakhi Rout, A hybridized ELM-Jaya forecasting model for currency exchange prediction, In Journal of King Saud University - Computer and Information Sciences, 2017, ISSN 1319-1578.

[46] Jingming Xue, SiHang Zhou, Qiang Liu, Xinwang Liu, Jianping Yin, "Financial time series prediction using $\ell 2,1$ RF-ELM", In Neurocomputing, 2017, ISSN 0925-2312.

[47] F. Wang, Y. Zhang, H. Xiao, L. Kuang and Y. Lai, "Enhancing Stock Price Prediction with a Hybrid Approach Based Extreme Learning Machine," 2015 IEEE International Conference on Data Mining Workshop (ICDMW), Atlantic City, NJ, 2015, pp. 1568-1575. https://doi.org/10.1109/ICDMW.2015.74

[48] Nargess Hosseinioun, "Forecasting Outlier Occurrence in Stock Market Time Series Based on WaveletTransform and Adaptive ELM Algorithm", Journal of Mathematical Finance, 2016, 6, 127-133. https://doi.org/10.4236/jmf.2016.61013.

[49] Alexander Grigorievskiy, Yoan Miche, Anne-Mari Ventela, Eric Severin, Amaury Lendasse, "Long-term time series prediction using OP-ELM", Neural Networks 51 (2014) 50-56. https://doi.org/10.1016/j.neunet.2013.12.002.

[50] Fang Zhijun; Zhao Jing; Fei Fengchang; Wang Qiangying; He Xin, "An approach based on multi-feature wavelet and ELM algorithm for forecasting outlier occurrence in Chinese stock market." Journal of Theoretical \& Applied Information Technology 49, no. 1 (2013).

[51] Simon Haykin, "Neural Networks: A Comprehensive Foundation", 2nd Ed., Pearson publication.

[52] Y. F. Sun, Y. C. Liang, W. L. Zhang, H. P. Lee, W. Z. Lin, L. J. Cao, "Optimal partition algorithm of the RBF neural networkand its application to financial time series forecasting", Neural Computation\& Application (2005) 14: 36-44 https://doi.org/10.1007/s00521-0040439-7.

[53] C. Quek, P. Cheng, A. Jain, "Predicting Impact of News on Stock Price: An Evaluation of Neuro Fuzzy Systems", IEEE Congress on Evolutionary Computation, CEC 2007, pp.1226-1233, IEEE 2007. https://doi.org/10.1109/CEC.2007.4424610.

[54] Hsuan-Ming Feng, Hsiang-Chai Chou, "Evolutional RBFNs prediction systems generation in the applicationsof financial time series data", Expert Systems with Applications, Vol. 38 (2011), 8285-8292. https://doi.org/10.1016/j.eswa.2011.01.009.

[55] Minakhi Rout, Babita Majhi, Usha Manasi Mohapatra,Rosalin Mahapatra, "Stock Indices Prediction Using Radial Basis Function Neural Network,"Swarm,Evolutionary, and Memetic Computing, pp. 285-293,2012.

[56] Wei Shen, Xiaopen Guoa, Chao Wub,Desheng Wuc "Forecasting Stockindices using radial basis function neural networks optimized byartificial fish swarm algorithm," Knowledge-Based Systems,vol.24( 3),pp. 378-385, 2011 https://doi.org/10.1016/j.knosys.2010.11.001. 